\title{
My Child Has a Mental Illness: Developing Parental Advocacy Skills ${ }^{1}$
}

\author{
Tracy DeCubellis, Victor W. Harris, and Martie Gillen²
}

Being a parent of a child who suffers from mental illness can be challenging. Children who suffer from mental and emotional disorders need parents who will advocate for them. Many parents experience intense grief and isolation when they learn their child has been diagnosed with a mental illness. However, parents can take proactive steps to improve their situation by learning about their child's diagnosis, finding community support, acknowledging strengths and weaknesses, discovering resources and barriers to care, and organizing important information related to their child's life.

Child mental health is an increasingly important issue in the United States. Approximately $20 \%$ of all children in the United States have a diagnosed mental health problem (Houtrow \& Okumura, 2011). According to the U.S. Department of Health and Human Services (2000), 10\% of all youth have a serious mental or emotional disorder that interferes with daily life. In fact, more than 4 million U.S. children under the age of 18 have been diagnosed with a serious mental illness, making childhood mental illness an issue that touches the lives of many American families (U.S. Department of Health and Human Services, 1999).

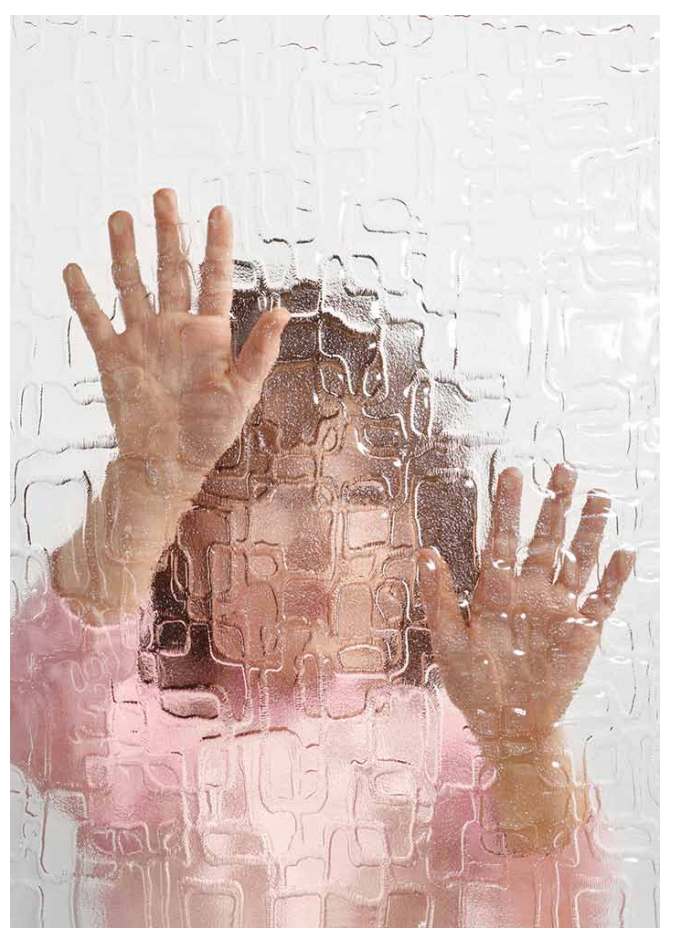

Figure 1. If your child is diagnosed with a mental illness, you will face major changes in your life. Being proactive about your child's care and advocating for him or her will help you and your child handle the illness successfully.

Credits: iStockphoto

1. This document is FCS2327, one of a series of the Department of Family, Youth and Community Sciences, Florida Cooperative Extension Service, Institute of Food and Agricultural Sciences, University of Florida. Original publication date April 2013. Visit the EDIS website at http://edis.ifas.ufl.edu.

2. Tracy DeCubellis, graduate student, Department of Family, Youth and Community Sciences; Victor W. Harris, assistant professor and family life education Extension specialist, Department of Family, Youth and Community Sciences; and Martie Gillen, assistant professor, Department of Family, Youth and Community Sciences; Florida Cooperative Extension Service, Institute of Food and Agricultural Sciences, University of Florida, Gainesville, FL 32611. 


\section{Helpful Information}

\section{Dealing with a Mental Illness Diagnosis GRIEF}

Having a child diagnosed with a mental illness can create substantial emotional and financial burdens for families and can cause major changes in their lives (Houtrow \& Okumura, 2011). It is normal for parents to experience grief when a child is diagnosed with mental illness. They may, for example, experience incredible sadness because such a diagnosis can mean a different future than what they envisioned for their child, including extended caregiving responsibilities. This type of grief is different from the traditional concept of "loss" typically experienced when a loved one dies because it is ongoing (McGinty, Worthington, \& Dennison, 2008). In addition, research suggests that parents of children who have more than one severe mental health diagnosis may also experience even higher levels of parental stress and grief (Houtrow \& Okumura, 2011).

Families who receive a mental health diagnosis for their children often face uncertainty, which can cause expected processes, milestones, and life goals to change (McGinty, Worthington, \& Dennison, 2008). These families should not expect to move through the grieving process in the same way as families who experience a death because new challenges may arise. For example, they may encounter new situations for their children, such as experiencing educational issues, seeking mental health services, dealing with emotional and behavioral manifestations of their child's disability, and planning for future employment or long-term care for their child (McGinty, Worthington, \& Dennison, 2008). These processes and milestones may bring ongoing feelings of loss as families are continually impacted by the realities of caring for a child with mental illness (L. Siemer, personal communication, October 19, 2012).

\section{GUILT, STIGMA, AND ISOLATION}

Parents often internalize responsibility when their child receives a mental illness diagnosis and may feel a sense of guilt (L. Siemer, personal communication, October 19, 2012). They may blame themselves and feel that they should have "seen it sooner" or wonder if their child's mental illness diagnosis was a result of their failure in some way.

Social attitudes and stigmas about child mental illness may lead to an increase in these feelings. For example, some people in the community may actually place blame for mental illness on the parents and families because of negative attitudes and perceptions associated with child mental illness (Mukolo, Heflinger, \& Wallston, 2010). As a result, parents may experience increased stress, strain, and social isolation as they care for their child while attempting to buffer themselves and their child from the negative attitudes and perceptions of others (Mukolo, Heflinger, \& Wallston, 2010). Parents may also stop taking their child to public places for fear that their child's emotional or behavioral problems will be triggered and result in negative reactions and judgments (L. Siemer, personal communication, October 19, 2012).

Additionally, extended family members and friends may not understand emotional and behavioral problems, or they may have stereotypes against mental illness that create strain for parents. For example, it may not be unusual for parents of children with mental illness to be criticized or even to be told "it's in your imagination" when they discuss their child's issues with extended family members (L. Siemer, personal communication, October 19, 2012). Friends may also distance themselves from families caring for children with mental illness for similar reasons (McGinty, Worthington, \& Dennison, 2008).

Many families may also experience difficulty maintaining friendships, community involvement, and extended family relationships because of the stigma and lack of understanding others may have toward mental illness. Faced with fewer friends and family members for support, families can feel isolated from others. Taking into account these factors, Disability Rights Florida Advocate/Investigator Linda Siemer says, "The isolation of families impacted by mental illness is incredible" (personal communication, October 19, 2012).

\section{Things You Can Use How to Advocate for Your Child with Mental IIIness FIND SUPPORT}

Families of children with mental illness may experience loss of support and isolation, so it is important to find new and multiple areas of support. Parents may have built-in supports throughout the community, such as extended family members, church and faith-based groups, or friends (McGinty, Worthington, \& Dennison, 2008). Additionally, therapists and psychiatrists often host support groups for patients or family members to provide a way for families to connect with others in similar situations. National mental health organizations such as the National Alliance on Mental Illness (NAMI) also sponsor local support groups for caregivers and family members of children with mental illness. Finding understanding peers can provide support 
and help alleviate caregiver stress and burden, as well as offer a resource of information based on the experiences of other families who are caring for a loved one with mental illness (McGinty, Worthington, \& Dennison, 2008).

\section{ACCENTUATE THE POSITIVE}

Disability advocates and state and federal governments recommend using "people-first language" when referring to people with disabilities. The U.S. Department of Labor and the Florida Agency for Persons with Disabilities explain that using people-first language empowers individuals by using positive language that recognizes the person instead of emphasizing a person's disability (U.S. Department of Labor, n.d.; Agency for Persons with Disabilities, n.d.). For example, instead of stating "My child is schizophrenic," a parent using people-first language might say, "My child has schizophrenia." By following this example, the child is considered as a person first and the diagnosis is stated second. Additionally, using the term "normal" to refer to persons without mental illness can insinuate that children with mental illness are abnormal, so it is recommended to avoid using labels such as "normal" or "typical" (U.S. Department of Labor, n.d.; Agency for Persons with Disabilities, n.d.).

Disability Rights Florida Advocate/Investigator Dr. Lee Clark also recommends that parents consider describing the way their child's disability manifests itself instead of referring to a disability label (personal communication, October 18, 2012). Describing your child's disability in terms of behavior across all life situations focuses on your child's daily functioning and needs as opposed to focusing on a mental health label and the perceptions or stigmas related to it (L.R. Clark, personal communication, October 18, 2012). One parent explained it this way:

My child was diagnosed with Reactive Attachment Disorder (RAD), but I learned fairly quickly that even therapists and doctors have different ideas of what this diagnosis means. It is much more helpful for me to explain that my child experienced early childhood trauma, and then to describe some of the behaviors my daughter exhibits regularly so they can get a better picture of her current level of functioning in different settings. I have found that describing my daughter's disability without using a diagnostic label such as RAD reduces stigma and allows people to care about her as a child rather than focusing on her disabilities. (Anonymous)

By continually using positive language about disabilities, parents of children with mental illness can reframe others' perceptions and emphasize the person instead of the diagnosis.

\section{BE PROACTIVE}

Parents can be extremely effective advocates for their children with the proper information and tools. The first step parents can take is to become familiar with their child's diagnosis and then determine if their child can receive community-based services (L.R. Clark, personal communication, October 18, 2012). Parents should understand the way their child's mental illness diagnosis presents itself in every life setting, such as at home, school, or community activities. This understanding may provide the basis for treatment and support services to meet their child's needs (L.R. Clark, personal communication, October 18, 2012). For example, parents might explain the ways that a child's disability impacts the child's behavioral, social, and emotional learning.

Similarly, instead of referring to a child's disability label, parents may describe a child's behavior and the way this behavior impacts learning. For example, a symptom of a child's disability may be poor peer relationships. The child might act in an aggressive way toward peers, which negatively impacts his or her learning. An important way parents can focus on their child's specific needs is by using descriptors that match a child's behaviors to show how the behaviors impact learning or functioning in different settings. By using these descriptors, the parents will be able to get the services and interventions needed for their child.

The second important step parents can take toward becoming an effective advocate is examining family and personal strengths, weaknesses, resources, and barriers to achieving goals and receiving needed services (Olin et al., 2010). This process is an essential step in becoming a strong parentadvocate. Knowledge is power, and it is critical that parents know themselves, their family, and their potential resources and barriers in order to provide the best possible care and future for their child.

The third step parents can take is to create a binder to hold important information that can be taken to doctor's appointments, school meetings, therapy visits, and other meetings as needed (L. Siemer, personal communication, October 19, 2012). A three-ring binder organized with sections such as "medical," "school," "therapy," "hospitalization," and "home" to summarize services, issues, successes, or action steps in these areas can be a helpful way for parents to organize well-rounded care for their child (L. Siemer, personal communication, October 19, 2012). The 
notebook can contain a parental statement summarizing the child's strengths and weaknesses, and any goals that the child, parents, physicians, teachers, or therapists set in each area.

Creating a notebook can also help parents keep track of practical issues, such as changes in medications or dosages, symptoms or side effects of medications, or other records. Documentation and record-keeping are crucial in advocating for a child to receive community-based programming and to ensure appropriate care across educational, medical, psychiatric, and therapeutic settings. Parents can also use the notebook to periodically re-examine strengths, weaknesses, and barriers, and to recognize successes over time. The overall process can provide parents with some of the encouragement needed to persevere in their advocacy efforts over the long term (Olin et al., 2010).

\section{Conclusion}

It can be a difficult time when parents learn their child has been diagnosed with a serious mental illness. Families often experience grief and isolation as a result of the stigma and misperceptions friends, family members, and the public have toward mental illness. If your child has been recently diagnosed with a mental illness, you may find it helpful to use Table 1 to track the progress you have made in your advocacy efforts so far and to list the items you still need to implement in the future. Once you have successfully completed all of the items on the chart, you may want to occasionally check for areas your family needs to reassess, such as new diagnoses, or changes in resources that may impact the availability of services. These steps can assist you in becoming an effective advocate for your child.

\section{Helpful Websites}

- National Association on Mental Illness: http://www.nami. org/

- National Disability Rights Network: http://www.ndrn. org/en/ndrn-member-agencies.html

- Disability Rights Florida: http://www.disabilityrightsflorida.org/

- Florida Agency for Persons with Disabilities: http://apd. myflorida.com/

- National Institute of Mental Health: http://www.nimh. nih.gov/index.shtml

\section{References}

Agency for Persons with Disabilities; State of Florida. (n.d.). Manners that matter: An etiquette guide for interacting with people with disabilities. Retrieved from http://apd. myflorida.com/brochures/apd-etiquette-brochure.doc

Houtrow, A. J. \& Okumura, M. J. (2011). Pediatric mental health problems and associated burden on families. Vulnerable Child Youth Study 6(3), 222-233. doi: 10.1080/17450128.2011.580144

McGinty, K., Worthington, R., \& Dennison, W. (2008). Patient and family advocacy: Working with individuals with comorbid mental illness and developmental disabilities and their families. Psychiatric Quarterly 79, 193-203. doi: 10.1007/s11126-008-9075-1

Mukolo, A., Heflinger, C. A., \& Wallston, K. A. (2010). The stigma of childhood mental disorders: A conceptual framework. Journal of the American Academy of Child \& Adolescent Psychiatry 49(2), 92-103.

Olin, S. S, Hoagwood, K. E., Rodriguez, J., Ramos, B., Burton, G., Penn, M., \& Jensen, P. S. (2010). The application of behavior change theory to family-based services: Improving parent empowerment in children's mental health. Journal of Child and Family Studies, 19(4), 462-470. doi: 10.1007/ s10826-009-9317-3

U.S. Department of Health and Human Services; U.S. Department of Education; U.S. Department of Justice. (2000). Report of the Surgeon General's conference on children's mental health: A national action agenda. Retrieved from http://www.ncbi.nlm.nih.gov/books/NBK44232/

U.S. Department of Health and Human Services. (1999). Mental health: A report of the Surgeon General. Retrieved from http://profiles.nlm.nih.gov/ps/retrieve/ ResourceMetadata/NNBBHS

U.S. Department of Labor; Office of Disability Employment Policy. (n.d.). Communicating with and about people with disabilities. Retrieved from http://www.dol.gov/odep/pubs/ fact/comucate.htm\#.UIcvYoY87jI 
Table 1. Child Advocacy Checklist for Parents

\begin{tabular}{|c|c|c|c|c|}
\hline \multicolumn{2}{|l|}{ Advocacy Step } & Yes & No & What I still need to learn/do \\
\hline \multicolumn{5}{|l|}{ I have researched my child's diagnosis. } \\
\hline \multicolumn{5}{|c|}{$\begin{array}{l}\text { I have created a notebook to organize information about my } \\
\text { child across all life settings. }\end{array}$} \\
\hline \multirow{4}{*}{$\begin{array}{l}\text { I can explain how my child's disability } \\
\text { manifests in the following settings: }\end{array}$} & Home & & & \\
\hline & School & & & \\
\hline & Community & & & \\
\hline & Therapy/Medical & & & \\
\hline \multirow[t]{4}{*}{ I have listed my family's: } & Strengths & & & \\
\hline & Weaknesses & & & \\
\hline & Resources & & & \\
\hline & Barriers & & & \\
\hline \multirow{3}{*}{$\begin{array}{l}\text { I have identified support for my family } \\
\text { from the following areas: }\end{array}$} & Friends/Family & & & \\
\hline & $\begin{array}{l}\text { Church/Faith } \\
\text { Community }\end{array}$ & & & \\
\hline & Support Groups & & & \\
\hline
\end{tabular}

